\title{
PYROLYSIS OF PLASTIC WASTE TO ENVIRONMENTALLY FRIENDLY PRODUCTS
}

\author{
UMESH PANDEY, JAN ARILD STORMYR, ALIREZA HASSANI, \\ RAJAN JAISWAL, HILDEGUNN H. HAUGEN \& BRITT M. E. MOLDESTAD \\ University of South-Eastern Norway, Norway
}

\begin{abstract}
Pyrolysis of plastics is one of the efficient ways to recover plastic waste. Pyrolysis refers to a thermal degradation of long-chain organic molecules into smaller hydrocarbons. Many ongoing research studies are trying to gain a better understanding of the pyrolysis technology with the aim of establishing new industrial processes for plastic recycling. The pyrolysis process can thermally degrade plastics or a mixture of biomass and plastics (co-pyrolysis) in the absence of oxygen. Temperature has the most impact on pyrolysis. Other processes to use in the conversion of plastic wastes into valuable products, are steam cracking and gasification. The objective of this study is to find the best operation conditions for conversion of plastic wastes in a fluidized bed reactor. A comprehensive literature study, experimental tests and computational particle fluid dynamics (CPFD) simulations are performed. A fluidized bed reactor is one of the most promising reactors for conversion of plastics in a continuous process. Experimental tests were performed to investigate the optimal operational conditions for conversion of plastics in a bubbling fluidized bed reactor. Steam was used as the fluidizing agent and sand as the bed material. From literature, it was found that the best temperature to avoid liquefaction in the reactor is $600^{\circ} \mathrm{C}$ or higher. The minimum fluidization velocities for steam at $600^{\circ} \mathrm{C}$ was found to be $0.18 \mathrm{~m} / \mathrm{s}$. CPFD simulations were performed and the computational result agreed well with the experimental data regarding minimum fluidization velocity. The CFPD model was further used to study the conversion of biomass to a product gas. The product gas contained $22 \% \mathrm{CO}, 7.5 \% \mathrm{H}_{2}$ and $7 \% \mathrm{CH}_{4}$. Based on the literature review, the experimental results and the simulations, this study recommends investigation of conversion of plastics and biomass in a bubbling fluidized bed reactor. The study concludes that thermal co-pyrolysis or co-gasification of biomass and plastics at temperatures above $600^{\circ} \mathrm{C}$ using sand as the bed material and steam as the fluidizing gas give reliable operating conditions for the future studies. A proper biomass to plastics ratio should be used to avoid melting of plastics in the feeding system and in the reactor. It is crucial to operate the reactor well above the minimum fluidization velocity, to avoid defluidization.
\end{abstract}

Keywords: plastic wastes, pyrolysis, catalysts, co-pyrolysis.

\section{INTRODUCTION}

Plastics have become an integral part of human life, and during the past 50 years, the commercial use of plastics has increased dramatically. A very large part of plastics ends up in municipal waste and poses problems with waste management. Monomers used in plastic production come from fossil fuels and they are non-biodegradable by nature. Hence, a strong plastic waste management solution is crucial [1]. The European commission is planning to implement a circular economy with a key focus on plastics. The objective is to ensure that all plastic packaging is reused or recycled by the year 2030 [2]. This commitment ensures that the plastics industry operates in a more sustainable way.

Different technologies are available for plastic waste recovery. Gasification, incineration and torrefaction serve the purpose of waste to energy principle of waste management. However, the utility of energy recovered from those processes is limited. The products from pyrolysis are oil and monomers, which can substitute diesel fuel and monomers for plastic production. In addition to higher recovery value, the primary driving factor at present is the global warming issues and stricter emission rules which are forcing forward mechanisms to 


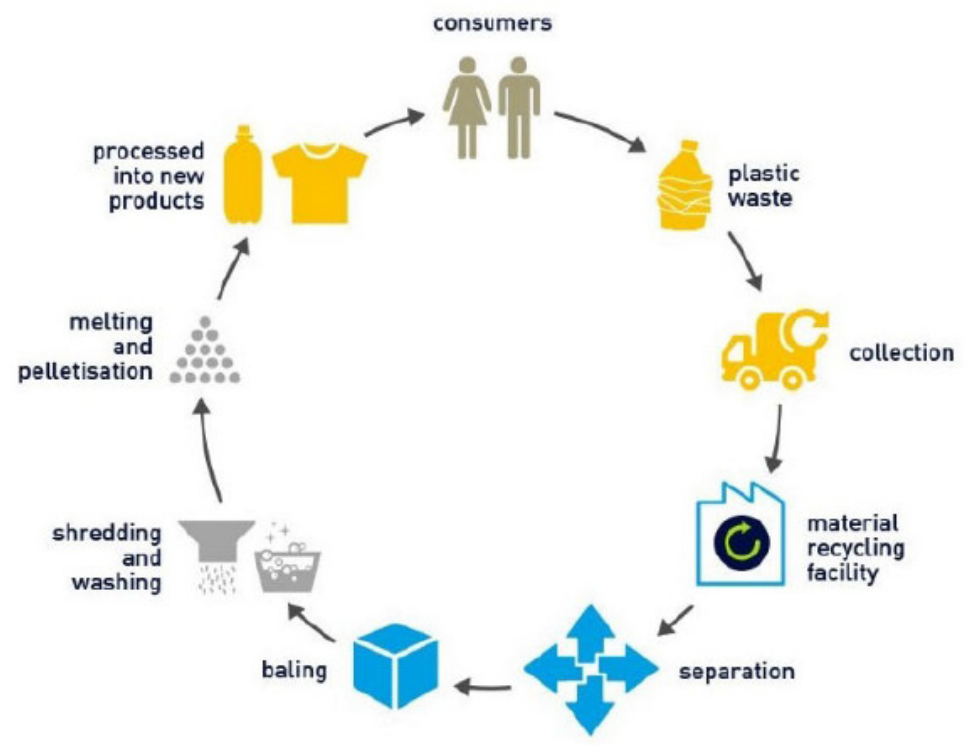

Figure 1: Plastic recycling [5].

recover valuable plastic wastes that are usually incinerated or sent to landfills [3], [4]. Fig. 1 shows the plastic recycling process.

The use of plastics has increased dramatically in the recent years. The upsurge in plastics consumption has raised the critical question of plastic waste management and a proper addressing of the problem is needed. There are several practices in modern waste management handling. The most common principles are reduce, reuse, and recycle (recovery). Reuse of waste plastic is not so popular since plastics lose their properties due to environmental effects and contaminants arising from its use. In addition to degradation of properties, the presence of internal additives limits the reuse. On the other hand, the knowledge of plastic recycling is inadequate as synthetic plastics have been available for only five decades. Among many recycling methods, pyrolysis is one of the prominent methods for plastic wastes management. Research on new efficient processes and modification of existing processes is always valuable.

The pyrolysis process is a complicated process with a history of only five decades. Many projects are implementing the pyrolysis process with the urge of recovering plastics as monomers or liquid fuel. Researchers have also focused on co-pyrolysis of biomass and plastics waste, which effectively pyrolyses waste plastics without separating it from other wastes. However, the primary concern in pyrolysis processes has been the wide range of pyrolytic products arising based on the feed mixture and the pyrolytic process condition. For this reason, a literature review of the pyrolysis processes is essential to gain an in-depth insight of products from the existing processes.

As pyrolysis is a thermal degradation process, efficient heat transfer increases the efficiency of the process. However, plastics have low heat conductivity, which results in nonuniform temperature distribution in the plastics feed. Due to this non-uniform heat distribution, a wide range of by-products may be produced. A literature study on the pyrolysis processes is performed to find an efficient solution to existing problems. 


\section{OVERVIEW OF POLYMERS AND THE PYROLYSIS PROCESS}

\subsection{Polymers}

Polymer is a Greek word, which refers to many units. The smaller units, monomers, repeat themselves to form a large polymer molecule. The process of forming a large molecule from constituent monomers is the polymerization process. Plastic polymers are synthetic polymers that are synthesized (polymerized) in an artificial environment. Plastic polymers are of two categories, thermoplastics and thermosetting plastics, based upon the thermal behaviour. Thermoplastics like polypropylene (PP) and polyethylene (PE), soften with increasing temperature and then melt without losing their chemical properties. Thermosetting plastics like Bakelite harden with increasing temperature and change their molecular structure [3], [6]. This study focuses on pyrolysis of different types of thermoplastics. Table 1 gives a list of thermoplastics, the corresponding monomers, and their practical application [7].

Table 1: Thermoplastics, corresponding monomer, and their practical application.

\begin{tabular}{|l|l|l|}
\hline Polymers & Monomer & Application \\
\hline $\begin{array}{l}\text { Low-density } \\
\text { polyethylene (LDPE) }\end{array}$ & Ethylene & $\begin{array}{l}\text { Packaging, wires and cables insulation, toys, } \\
\text { flexible bottles, coatings, housewares }\end{array}$ \\
\hline $\begin{array}{l}\text { High-density } \\
\text { polyethylene (HDPE) }\end{array}$ & Ethylene & $\begin{array}{l}\text { Bottles, drums, pipes, conduit, sheet, film, } \\
\text { wire, and cable insulation }\end{array}$ \\
\hline Polypropylene (PP) & Propylene & $\begin{array}{l}\text { Automobile and appliance parts, furniture, } \\
\text { carpeting }\end{array}$ \\
\hline Polystyrene (PS) & Styrene & $\begin{array}{l}\text { Packaging (foam and film), foam insulation, } \\
\text { housewares }\end{array}$ \\
\hline $\begin{array}{l}\text { Polyvinyl chloride } \\
\text { (PVC) }\end{array}$ & Vinyl chloride & $\begin{array}{l}\text { Construction, rigid pipes, flooring, wire, and } \\
\text { cable insulation }\end{array}$ \\
\hline $\begin{array}{l}\text { Poly(methyl } \\
\text { methacrylic)acid } \\
\text { (PMMA) [6] }\end{array}$ & $\begin{array}{l}\text { Methyl } \\
\text { methacrylic acid }\end{array}$ & $\begin{array}{l}\text { Bio-medicinal application, and } \\
\text { nanotechnology }\end{array}$ \\
\hline
\end{tabular}

Biopolymers or biomass are natural polymers which are derived from plants and animals. Bio-wastes are rich in plant-based polymers like lignin and cellulose. Biopolymers also degrade like thermoplastics, which makes pyrolysis a suitable technique for the bio-waste management. Since the access to biomass is considerable, co-pyrolysis of a mixture of biowastes and plastic wastes is an interesting approach [3].

\subsection{Pyrolysis processes}

Pyrolysis is a thermochemical decomposition of polymers (organic or synthetic) in absence of oxygen [3], [8]. Pure nitrogen is used in the pyrolysis to provide the required neutral environment and to transfer the products out of the reactors [6]. Pyrolysis can be purely thermal or thermo-catalytic. The product from thermal pyrolysis is mostly gaseous. The gaseous products of the thermal pyrolysis cover as much as $93 \%$ of total recovered products with a large variety of components. Thermo-catalytic pyrolysis enhances the degradation of polymers at temperatures in the range of $350-600^{\circ} \mathrm{C}$ [9]. Catalytic pyrolysis employs different catalysts, such as zeolite-based catalyst (ZSM-5), CoMo oxide/ $\mathrm{Al}_{2} \mathrm{O}_{3}$, and $\mathrm{ZnO}$ [6]. Use of catalysts enhances liquid recovery and decreases the content of char and ash. 
Fig. 2 shows a schematic presentation of a pyrolytic plant for biomass pyrolysis. The screw feeder feeds the biomass to the pyrolysis chamber. The gas burner supplies the required heat to raise the temperature of the feed to $300-600^{\circ} \mathrm{C}$. Then, the biomass begins to degrade to the gaseous and the solid products. The gases contain high-density components that are condensable, and low-density components that are not condensable at ambient temperature and pressure. The solid particles contain ashes and char. In the case of virgin thermoplastics, such as PP and PE, the solid products only contain char and waxes. The same process is also used for plastics pyrolysis.

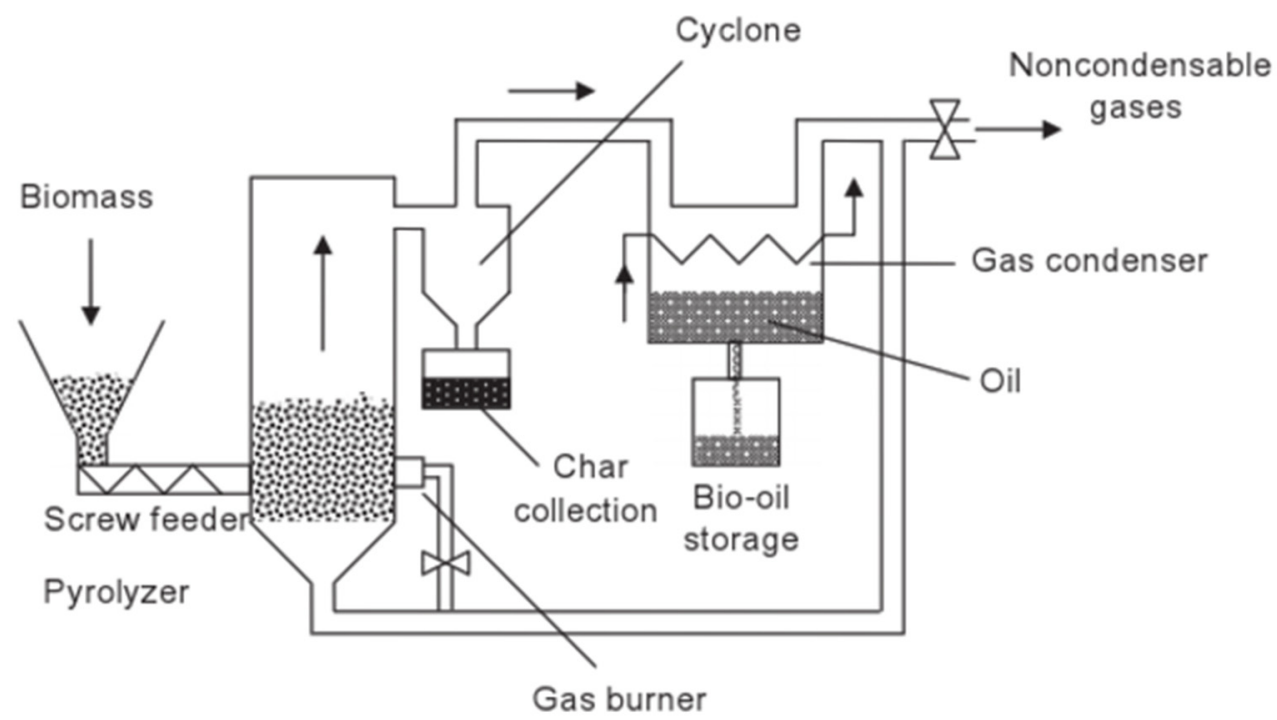

Figure 2: Simple schematic layout of a pyrolysis plant [3].

The chemical reaction occurring in the pyrolytic chamber [3] is presented in eqn (1)

$$
\mathrm{C}_{n} \mathrm{H}_{m} \mathrm{O}_{p} \text { (biomass or polymer) } \stackrel{\text { heat }}{\longrightarrow} \sum_{\text {liquid }} \mathrm{C}_{x} \mathrm{H}_{y} \mathrm{O}_{z}+\sum_{\text {gas }} \mathrm{C}_{a} \mathrm{H}_{b} \mathrm{O}_{c}+\mathrm{H}_{2} \mathrm{O}+\mathrm{C} \text { (char) } \text {. }
$$

There are two different types of pyrolysis processes based upon residence time of gas in the pyrolytic chamber. In the fast pyrolysis process, a short residence time of $0.5-10 \mathrm{~s}$ and a heating rate of $10-200^{\circ} \mathrm{C} / \mathrm{s}$ are used. The fast pyrolysis results in high liquid yield with low solid and gas yields. In a slow pyrolysis process, the gas residence time is significantly longer $(450-550 \mathrm{~s})$, and the heating rate is lower $\left(0.1-1^{\circ} \mathrm{C} / \mathrm{s}\right)$ compared to the fast pyrolysis process. In comparison to a fast pyrolysis process, the slow pyrolysis process gives lower liquid yield and higher solid and gas yield [10], [11].

\section{PYROLYSIS OF PLASTICS WASTES}

Plastics wastes are propitious sources for production of diesel fuels or monomers, due to the high heating value and high availability. The catalytic fast pyrolysis process yields liquid rich in hydrocarbons $\left(\mathrm{C}_{11}-\mathrm{C}_{20}\right)$, which has similar thermal and chemical properties as diesel. Although recovery of monomers is more valuable than liquid fuel recovery, it is difficult to separate different monomers from plastic wastes. 


\subsection{Pyrolysis to produce diesel fuel}

The optimal pyrolysis temperature for thermal degradation of plastic wastes into liquid fuel is found to be in the range of $450-700^{\circ} \mathrm{C}$. However, the addition of catalyst enhances the plastics degradation at lower temperatures $\left(230-350^{\circ} \mathrm{C}\right)$. At temperatures of $230-450^{\circ} \mathrm{C}$, the product is mainly liquid with only small amounts of gas components. At higher temperatures $\left(450-700^{\circ} \mathrm{C}\right)$, a considerable amount of gas is produced together with the pyrolytic liquid. The heating time also affects the products from the pyrolysis process. In a batch operation, increasing time will decrease the liquid yield and instead increase the solid and char yield.

Most commonly used catalysts are a natural zeolite and, in some studies, synthetic zeolite, MCM-41. It is observed that the catalyst used in pyrolysis improves the liquid yield (quality and quantity) [12]. Although Rehan et al. [13] obtained higher liquid yield with the thermal pyrolysis of low-density polyethylene $(80.8 \% \mathrm{w} / \mathrm{w})$ in comparison to a catalytic process $(54 \% \mathrm{w} / \mathrm{w})$, the catalytic process gives higher aromatic liquid yield compared to a thermal process. Catalysts also increase the aromatics yield due to their higher selectivity towards the aromatics production [13]. The composition of components in the pyrolytic liquid varies with the catalyst as a specific catalyst has higher selectivity for a specific range of hydrocarbons. The Zeolite catalyst has higher selectivity regarding the liquid components $\mathrm{C}_{8}-\mathrm{C}_{12}$, and MCM-41 has higher selectivity regarding heavier hydrocarbons $\left(>C_{13}\right)$ [14].

Both batch processes and continuous processes are used to produce pyrolytic liquid. Fluidized bed reactors are extensively used in continuous processes. The yield of pyrolytic liquid varies significantly with the feed used in the process. In general, PP as feed, produces the highest liquid yield (up to 80\%) [15]. Liquid obtained from thermal pyrolysis of PP, has the highest liquid content with a distillation temperature of $<170^{\circ} \mathrm{C}$. However, the heating value of the pyrolytic liquid for all kind of polyolefin pyrolysis is $44-46 \mathrm{MJ} / \mathrm{kg}$, which is about the same as for diesel or gasoline. Thus, the pyrolytic liquid is suitable for use as a liquid fuel.

It can be concluded that the liquid fuel produced in both the thermal and catalytic pyrolysis is a function of reaction time, temperature and feedstock. The liquid fuel obtained in both thermal and catalytic pyrolysis can be used for various applications if it is purified using fractional distillation.

\subsection{Pyrolysis processes to produce monomers}

Waste plastics can be recovered chemically to its monomers via one-step conversion or twostep conversion processes. The one-step conversion process uses high temperature to crack the polymers to their constituent monomers, and then the monomers are separated from other by-products via fractional distillation. In the case of using polyolefins (PP, LDPE, and HDPE) as feed to the one step monomer recovery process, a range of olefins (monomers of PP, LDPE, and HDPE) along with paraffins (gases) are obtained. One step cracking of PS and PMMA produces their constituent monomers (styrene and MMA), which are liquids at room temperature. The optimum yield of monomers from pyrolysis of PMMA and PS is obtained at temperatures of $400-500^{\circ} \mathrm{C}$, and the yield of monomers decreases with increasing pyrolysis temperature [16].

The yield of olefins (ethene and propene) in the case of thermal pyrolysis of polyolefins (PP, LDPE, HDPE) is highest at temperatures in the range of $700-750^{\circ} \mathrm{C}$. The reason why high yield is obtained at higher temperatures is that liquid and waxes, which might have been formed at low temperatures, crack to gases (olefins) and char. However, in the case of 
catalytic pyrolysis, the peak yield corresponds to the pyrolysis temperature of about $650^{\circ} \mathrm{C}[16]$.

Almost all single-step conversion processes are using fluidized bed reactors to investigate monomer recovery from waste plastics (especially polyolefins). Nitrogen has been used as a heat carrier and fluidizing agent in all those processes. However, the use of steam in a fluidized bed can be an exciting approach to minimize the severity of tar deposition in pipes and minimize non-uniform heat distribution as steam has higher heat capacity than nitrogen [17].

Two-step processes can also be used to recover plastic wastes as monomers. In the first step, different pyrolytic techniques are used to produce a pyrolytic liquid (naphtha). In the next step, the pyrolytic liquid is cracked using conventional cracking or steam cracking to get olefins as the main products [18], [19]. The cracking with steam is both cost-effective and highly efficient.

\subsection{Co-pyrolysis of biomass and plastic wastes}

Liquids from co-pyrolysis are rich in aromatics and can substitute fuels in the automotive. The liquid requires a minimum of upgrading before it can be used as a commercial fuel. Co-pyrolysis is a more energy efficient process compared to individual pyrolysis. Higher energy efficiency is a consequence of the synergetic effect of plastics and biomass feed during co-pyrolysis. This synergetic effect was confirmed by a reduced activation energy of co-pyrolysis in comparison to separate pyrolysis of plastics and biomass. As a result, solid waste management (biomass and plastics) at low energy costs is possible.

Moreover, the mixing of plastics and biomass results in an increase in liquids rich in aromatics, and at the same time a decrease in the solid (ashes and char) and gas (oxides of hydrocarbons) yield. Plastics have higher hydrogen to carbon ratio compared to biomass, and the excess hydrogen enhances aromatization, thus reducing the production of carbon oxides and water. The primary aromatic compounds present in the co-pyrolysis of a blend of biomass and plastics are benzene, xylene, toluene, p-xylenes, phenols and ethyl benzenes. These compounds have similar properties to heating fuel and hence can substitute diesel as a commercial fuel. Moreover, these compounds have a wide application in various organic synthesis; toluene in benzene, urethane and pharmaceuticals synthesis, Xylenes in the manufacture of dyes, films, and fibers. In addition to enhanced aromatic yield when mixing plastics into biomass, catalysts such as HZSM-5 can enhance the aromatic yield to as high as $82 \%$ for a blend of $80 \%$ plastics, $10 \%$ pine and $10 \%$ tire at $420^{\circ} \mathrm{C} \mathrm{[20],} \mathrm{[21].}$

The Cobalt catalyst has higher hydrogen selectivity (up to $47 \% \mathrm{v} / \mathrm{v}$ in gas) in comparison to other organic products when a 5:1 blend of biomass and plastics is used in the pyrolysis. This process unlocks an entirely new approach to synthesize hydrogen from solid waste. However, increased biomass content in plastics favours catalytic (mainly investigated for HZSM-5) deactivation, which can be nullified by increasing the catalyst to feed ratio. It is necessary to investigate the trade-off for the biomass to plastics ratio to optimize the hydrogen yield as well as minimize catalyst deactivation. On the other hand, temperature plays a significant role regarding the co-pyrolytic product. The product composition changes drastically when the operating temperature is varied significantly. Co-pyrolysis using the HZSM-5 catalyst and temperatures below $400^{\circ} \mathrm{C}$ gives high content of solid products. By increasing the temperature from $400^{\circ} \mathrm{C}$ to $600^{\circ} \mathrm{C}$, the aromatic yield increases. However, at a temperatures higher than $600^{\circ} \mathrm{C}$, co-pyrolysis of a blend of plastics and biomass is beneficial to produce gases rich in paraffins and olefins [22]-[24]. 


\section{EXPERIMENTAL AND COMPUTATIONAL STUDY}

\subsection{Experimental set-up}

A lab-scale bubbling fluidized-bed (BFB) reactor with a feed capacity of $3-5 \mathrm{~kg} / \mathrm{h}$, is used for the initial experimental tests. A schematic of the reactor is presented in Fig. 3. The experimental rig is composed of a feeding system, a fluidized-bed reactor, a pre-heating system for the fluidizing gas stream, a sampling line and an exhaust line.

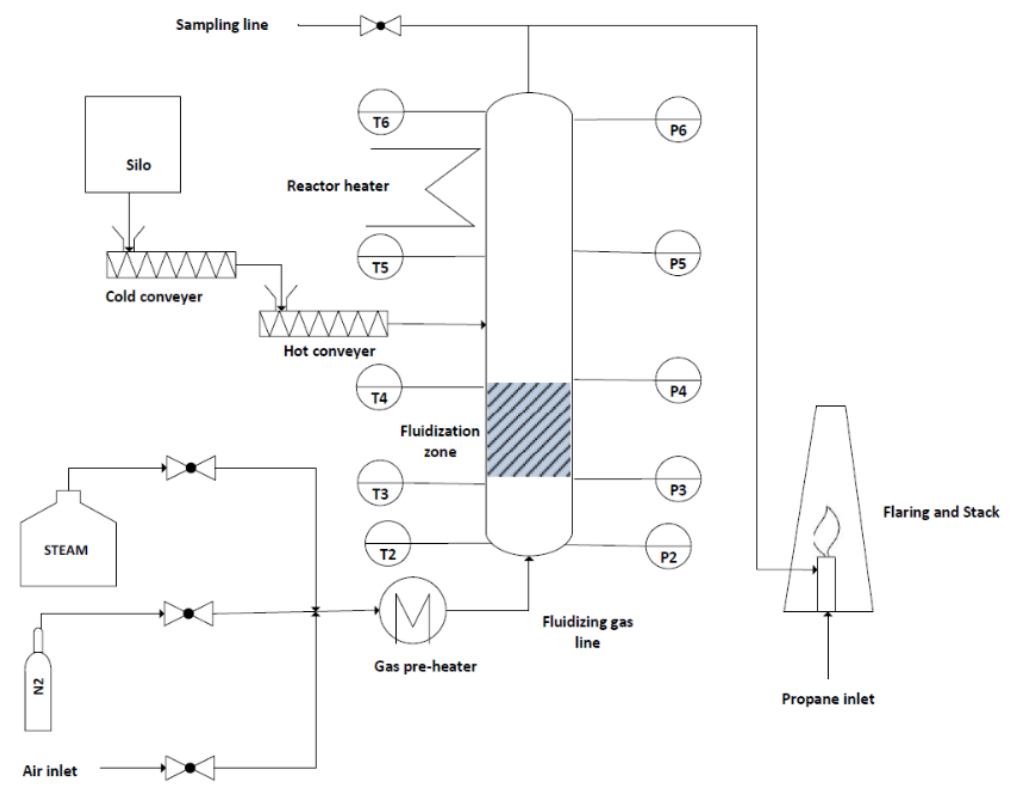

Figure 3: Schematic diagram of the bubbling fluidized bed reactor.

The feeding system consists of a silo followed by a cold and a hot screw feeder. The cold screw feeder conveys the feed from the silo to the hot screw feeder. The hot screw feeder transports the feed into the reactor. The reactor is a cylindrical vessel with an inner diameter of $0.1 \mathrm{~m}$ and a height of $1.0 \mathrm{~m}$ and is insulated by mineral wool. Three heating elements of $3 \mathrm{~kW}$ capacity are embedded around the reactor vessel to maintain and control the temperature in the reactor. In the preliminary experiments, air is used as the fluidizing agent instead of nitrogen or steam. The air is flowing through a pre-heater composed of six heating elements with a total capacity of $18 \mathrm{~kW}$. The exhaust line starts at the top of the reactor, and transports the product gases from the reactor to the flaring system. At the top of the reactor there is also a sampling line.

\subsection{Experimental results}

It is essential to determine the operating conditions and understand the fluidization properties of the bed, before plastics are fed to the reactor. An analysis of data obtained from the fluidization experiments helps to find the optimum process parameters such as the gas flow rate at different temperatures, and also to understand the flow behaviour of the fluidized bed. 
The results can be further used for scale-up of the lab-scale reactor to a pilot plant for the pyrolysis process.

The experiments aim to determine the minimum fluidization velocity at temperatures in the range of $500-600^{\circ} \mathrm{C}$ using quartz sand as the bed material. The results from the experiments are used to determine a suitable gas velocity to ensure fluidization for the future experiments with plastic wastes. The particle size distribution for the sand particles is measured using sieving analysis. The particle sizes were in the range of $45-710 \mu \mathrm{m}$, and the mean size was $305 \mu \mathrm{m}$.

The experiments were performed without polymers, and with air as the fluidizing agent. Air has about the same properties as nitrogen, and can therefore be used for the initial tests where no reactions occur. The bed material (sand) was filled into the reactor to observe the fluidization properties of the sand. Dry air entered the air line from a 7 bars compressor. The reactor is open to atmosphere. Experiments were performed at $600^{\circ} \mathrm{C}, 550^{\circ} \mathrm{C}$, and $500^{\circ} \mathrm{C}$ to determine the minimum fluidization velocity in a temperature range that is relevant for pyrolysis. The experiments are run using a range of gas velocities. The pressure drop and the pressure drop variations are monitored at each velocity. The average pressure drop over the bed $(\triangle \mathrm{P})$ and the standard deviation of pressure drop $(\mathrm{SD})$ are calculated, and the ratio $\mathrm{SD} / \Delta \mathrm{P}$ is plotted versus the superficial gas velocity. The results are presented in Figs 4-6 for the temperatures 500,550 and $600^{\circ} \mathrm{C}$, respectively. The minimum fluidization velocites are determined as shown in the figures. The experimental results show that the minimum fluidizing velocity decreases with increasing temperatures in the reactor. When the bed temperature is increased from $500^{\circ} \mathrm{C}$ to $600^{\circ} \mathrm{C}$, the minimum fluidization velocity decreases from $0.23 \mathrm{~m} / \mathrm{s}$ to $0.15 \mathrm{~m} / \mathrm{s}$. The decrease in minimum fluidization velocity with increasing temperature is mainly due to the increase in gas viscosity with temperature.

If steam is used as the fluidizing agent, the minimum fluidization velocities will increase compared to the values for air and nitrogen because steam has a considerably lower viscosity. The theoretical minimum fluidization velocity can be calculated based on the Ergun equation

$$
U_{m f}=\frac{d_{p}^{2} \cdot\left(\rho_{p}-\rho_{f}\right)}{150 \cdot \mu_{f}} \cdot \frac{\varepsilon_{m f}^{3} \cdot \varphi^{2}}{\left(1-\varepsilon_{m f}\right)},
$$

where $d_{p}$ is the particle diameter, $\rho_{p}$ is the particle density, $\rho_{f}$ is the fluid density, $\varepsilon_{m f}$ is the void fraction at minimum fluidization, $\varphi$ is the particle sphericity and $\mu_{f}$ is the fluid viscosity.

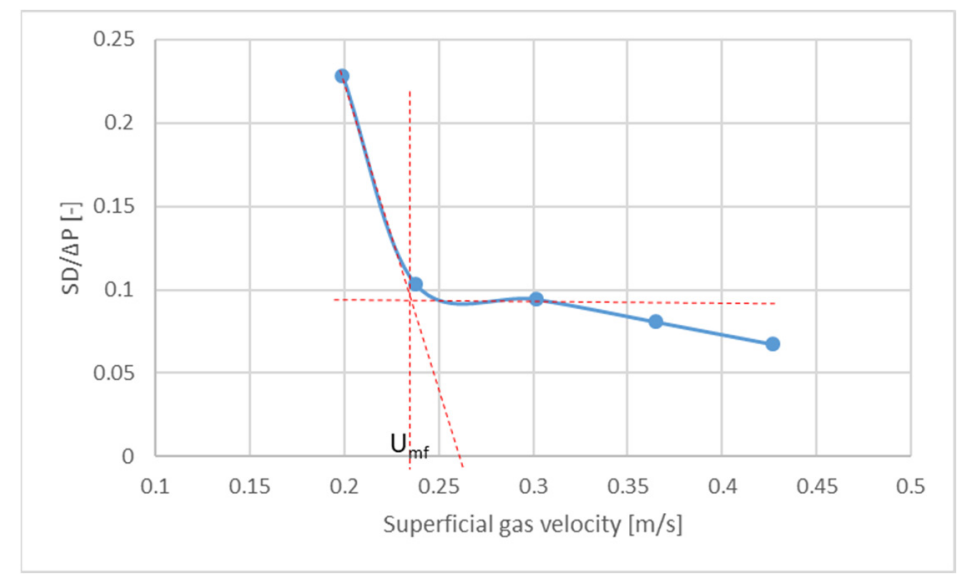

Figure 4: Relative pressure fluctuation versus gas velocity, $\mathrm{T}=500^{\circ} \mathrm{C}$. 


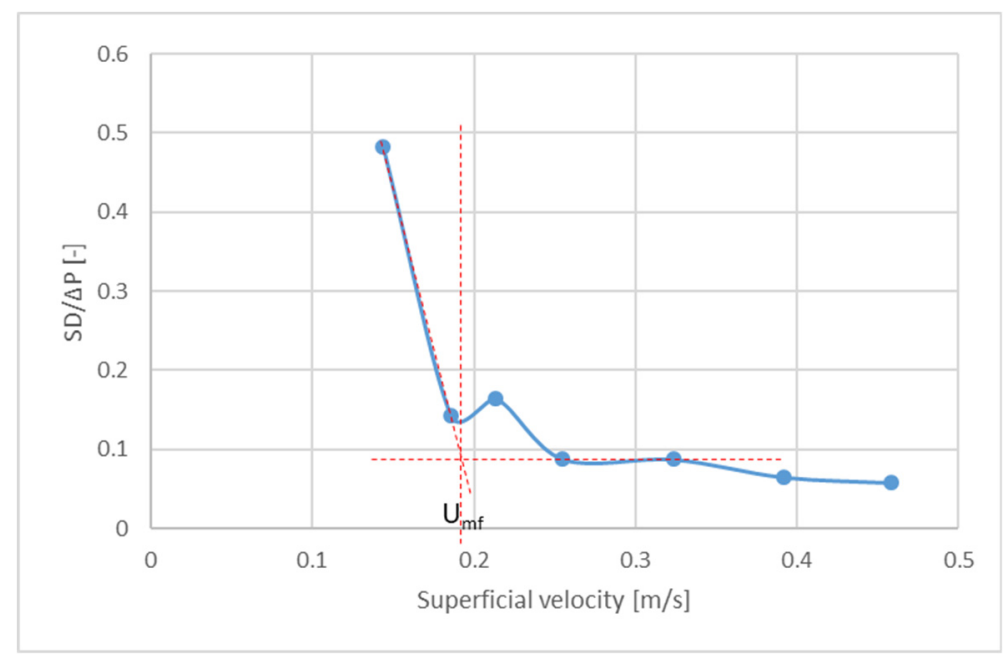

Figure 5: Relative pressure fluctuation versus gas velocity, $\mathrm{T}=550^{\circ} \mathrm{C}$.

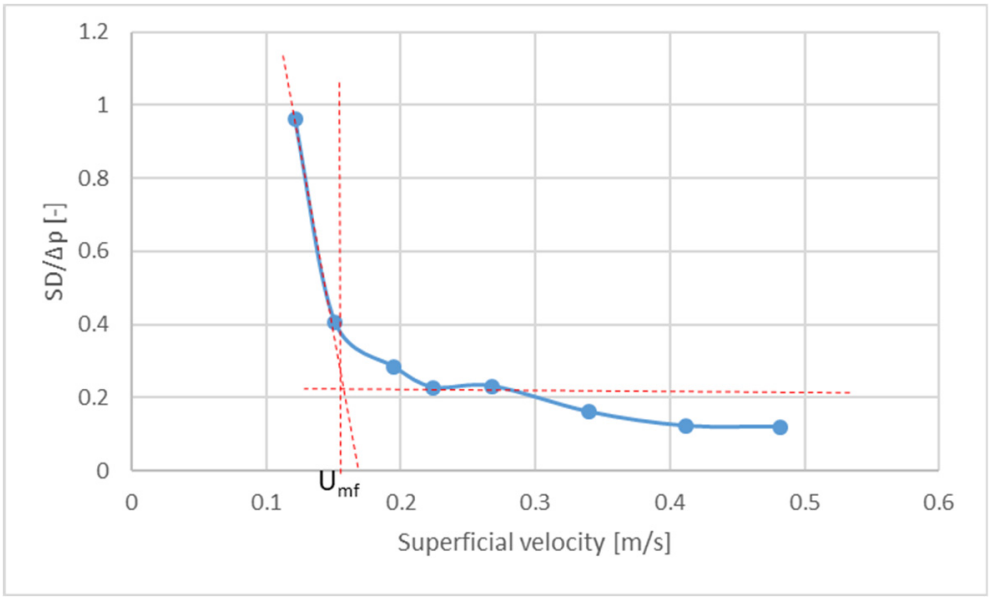

Figure 6: Relative pressure fluctuation versus gas velocity, $\mathrm{T}=600^{\circ} \mathrm{C}$.

As can be seen from eqn. (2), the fluid viscosity is the only parameter that will influence significantly the minimum fluidization velocity when the particle density and size are constant and the fluidizing agent is a gas with low density.

The minimum fluidization velocities for steam are calculated by multiplying the experimental minimum fluidization velocities for air with the air to steam viscosity ratio at the actual temperatures. The calculated values for steam are presented in Table 2 together with the experimental values for air.

The particle size distribution in the experiments ranged from $45 \mu \mathrm{m}$ to $710 \mu \mathrm{m}$, and segregation of particles may occur with time. If the largest particles dominate the fluidization, the minimum fluidization velocity may increase significantly. Segregation can also lead to 
Table 2: Minimum fluidization velocity for quartz sand at different temperatures.

\begin{tabular}{|c|c|c|}
\hline Temperature & $\begin{array}{c}\text { Minimum fluidization } \\
\text { velocity, air }\end{array}$ & $\begin{array}{c}\text { Minimum fluidization } \\
\text { velocity, steam }\end{array}$ \\
\hline $500^{\circ} \mathrm{C}$ & $0.23 \mathrm{~m} / \mathrm{s}$ & $0.28 \mathrm{~m} / \mathrm{s}$ \\
\hline $550^{\circ} \mathrm{C}$ & $0.19 \mathrm{~m} / \mathrm{s}$ & $0.23 \mathrm{~m} / \mathrm{s}$ \\
\hline $600^{\circ} \mathrm{C}$ & $0.15 \mathrm{~m} / \mathrm{s}$ & $0.18 \mathrm{~m} / \mathrm{s}$ \\
\hline
\end{tabular}

channeling and thereby need for higher gas velocity to keep the particles fluidized. It is crucial to keep the reactor in the fluidized regime to ensure good mixing and uniform temperature in the bed. The experimental pre-study is therefore important when planning the ideal operation conditions for conversion of plastics and biomass. Computational particle fluid dynamics (CPFD) simulations were performed to study the minimum fluidization velocity using steam as the fluidizing agent.

\subsection{Computational particle fluid dynamics simulations}

Computational particle fluid dynamics (CPFD) simulations are used to predict the minimum fluidization velocity for steam at $600^{\circ} \mathrm{C}$ when the bed material is sand with mean diameter of $305 \mu \mathrm{m}$ and spherisity 0.86 . The fluidized bed reactor was modelled as an open cylinder with inner diameter $0.1 \mathrm{~m}$ and height $1.0 \mathrm{~m}$. The CPFD model is developed using Barracuda VR, and the model has been validated against experimental data in previous studies. The CPFD numerical methodology incorporates the multi-phase-particle-in-cell (MP-PIC) method [25], [26], where particles with the same properties are grouped into parcels and each parcel is represented by one computational particle. The gas phase and the particle phase are modelled using the Eulerian and Lagrangian approaches respectively. The simulations are carried out using the Ergun drag model, which is valid for gas volume fractions lower than 0.8. The initial solid volume fraction was set to 0.54 and the maximum solid fraction was defined as 0.63 . The reactor geometry was divided into 4,800 cells. The boundary conditions were set as outlet gas pressure at the top and inlet superficial steam velocity at the bottom. To predict the minimum fluidization velocities, the simulations were run with superficial steam velocities ranging from $0.05 \mathrm{~m} / \mathrm{s}$ to $0.35 \mathrm{~m} / \mathrm{s}$. The time steps were set to $0.001 \mathrm{~s}$. The results are plotted and presented in Fig. 7, where the pressure drop is plotted as a function of the superficial gas velocity. Based on the plot, the simulated minimum fluidization velocity is found to be $0.165 \mathrm{~m} / \mathrm{s}$. The simulated minimum fluidization velocity for steam agrees well with the value estimated based on the experimental data. However, more experiments are needed to develop a robust model.

The CPFD model, including chemical reactions, was further used to simulate the reaction of biomass with steam at $600^{\circ} \mathrm{C}$. Fig. 8 shows the composition of the product gas as a function of time. The simulation was run for $800 \mathrm{~s}$ using superficial steam velocity of $0.2 \mathrm{~m} / \mathrm{s}$. The biomass was fed to the reactor at a mass flow rate of $2.5 \mathrm{~kg} / \mathrm{h}$. The composition of the product gas after $800 \mathrm{~s}$ is $22 \% \mathrm{CO}, 7.5 \% \mathrm{H}_{2}, 7 \% \mathrm{CH}_{4}, 3.5 \% \mathrm{CO}_{2}$ and the rest is steam. The steam is partly from the injected steam and partly from the humidity in the biomass. The steady state conditions are not reached after $800 \mathrm{~s}$, and the mole fractions of the components are still increasing. The simulation time needs to be extended to get the final composition. 


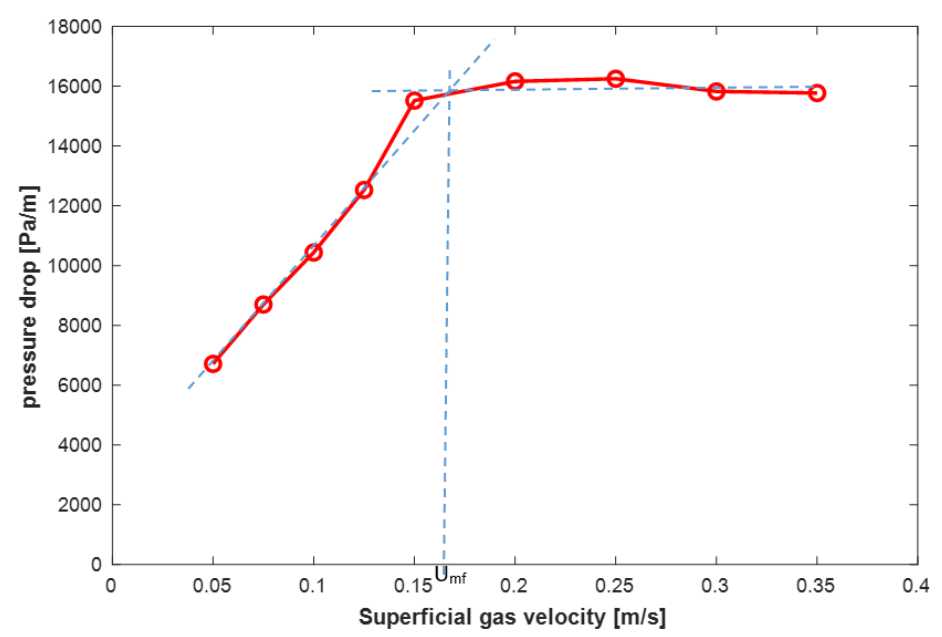

Figure 7: CPFD simulation of prediction of minimum fluidization velocity for steam at $600^{\circ} \mathrm{C}$.

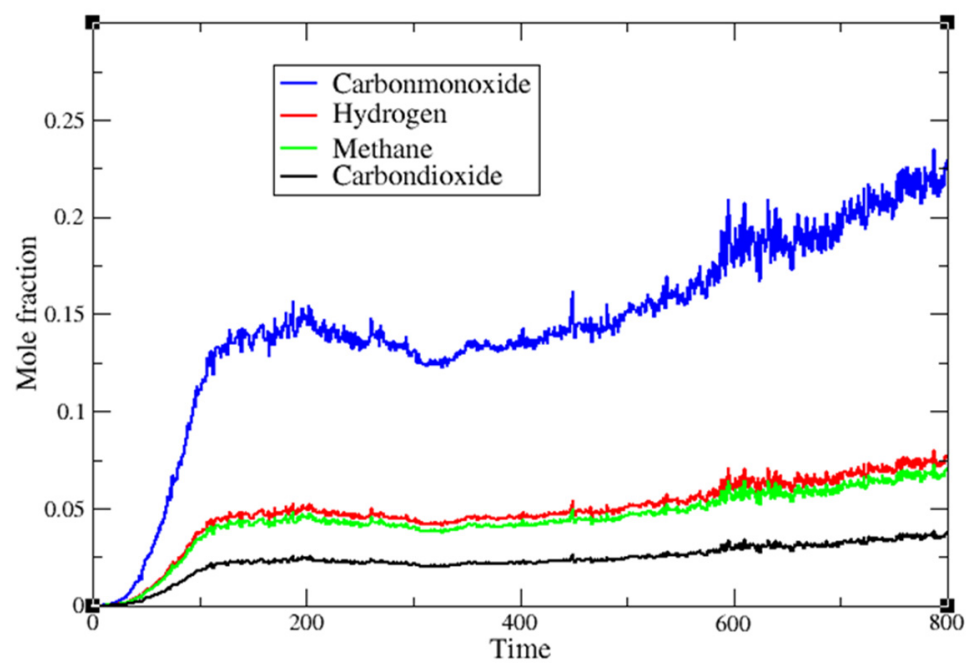

Figure 8: Composition of the product gas when biomass is used as feed in the pyrolysis process, at $600^{\circ} \mathrm{C}$ and at superficial gas velocity of $0.2 \mathrm{~m} / \mathrm{s}$.

\subsection{A proposal for the future pyrolysis experiment in the fluidized bed reactor}

The initial plan for this study was to study the pyrolysis of plastics in the lab-scale fluidized bed reactor presented in Fig. 3. The authors faced several challenges as the study progressed. Some of the identified challenges were liquefaction of the pyrolytic products in the flow pipes and sampling line. Thus, this study was only able to determine the minimum fluidization velocities at different temperatures and to suggest possible measures to resolve the 
challenges, which could be a stepping stone for the future experiments. Moreover, a suggestion of process variables that can minimize the potential hazards is proposed for the future experiments.

Based on the results, this study suggests using sand with mean particle size of about $300 \mu \mathrm{m}$ as bed material and fluidization velocity above $0.20 \mathrm{~m} / \mathrm{s}$ if steam is to be used as the fluidizing agent. The experiments should be carried out at $600^{\circ} \mathrm{C}$ or higher temperatures to avoid liquefaction in the system. Defluidization of the bed due to coating of melted plastics on the surface of the bed material is one of the major problems in pyrolysis of plastics. Hence, the operation conditions for the future experiments should be planed focusing on the relationship between the defluidization behavior and the feeding rate of plastics relative to the bed weight, the temperature in the bed and a mixture of polymers.

Recent studies on steam cracking of polyolefins show that polyolefins degrade to monomers when steam is used in the cracking process, and steam cracking will therefore be considered in the future research. In addition, gasification of plastic waste with steam will be tested out in the fluidized bed reactor.

In a high temperature operation, fluidized bed is one of the most efficient reactors, which can maintain uniform temperature as well as uniform heating rate. However, there are still challenges, which can initiate safety hazards when the reactor is used in conversion of plastics. The available fluidized bed reactor is specially designed for gasification of biomass. The products obtained from the gasification is a synthesis gas with $\mathrm{H}_{2}, \mathrm{CO}, \mathrm{CH}_{4}$ and $\mathrm{CO}_{2}$ as the main components. Therefore, the risk of liquefaction of the pyrolysis products has not been considered in the process design, and some essential modifications are necessary to eliminate possible liquefaction in the flow pipes during the pyrolysis process.

The risk of liquefaction in the pipes is significantly reduced if the plastics are converted to a product gas. Hence, an operating temperature of $600^{\circ} \mathrm{C}$ or higher is a reliable option when polyolefins are used as feedstocks.

The most critical issue is to feed the plastics into the reactor. The plastics have a low melting point (LDPE-109 to $125^{\circ} \mathrm{C}$ ), which could cause melting of the plastics in the hot screw feeder. The melted plastics stick to the wall of the feeder and agglomerate with other plastic feeds. These agglomerates can break down the whole setup and potentially cause an accident. Thus, instead of using pure plastics in the future research this study suggests using a mixture of biomass and plastics as feed to the fluidized bed reactor. The mixture is more straightforward to feed in comparison to the pure plastics, as the biomass or biomass ash will not melt at temperatures below $800^{\circ} \mathrm{C}$.

\section{CONCLUSION}

A litterature review is performed to investigate technologies and operation conditions for plastic waste recovery. Pyrolysis is one of the efficient ways to recover plastic waste as constituent monomers or pyrolytic liquid. The key factors that affect the quality and quantity of preferable products are the operating temperature in the reactor, types and composition of feedstocks, catalysts, reaction time and gas residence time. The operation temperature is the factor that dominates the outcome of the process. Pyrolysis of a blend of biomass and plastics gives products analogous to the pyrolysis of plastics together with aqueous liquids and carbon oxides. The use of catalysts and the amounts of plastics have a positive impact on the aromatic composition compared to pyrolysis of pure biomass. Other processes to use in convertion of plastic wastes into valuable products, are steam cracking and gasification.

Fluidized bed reactor is one of the most promising reactors for conversion of plastics in a continuous process. Experimental tests were performed to investigate the optimal operational conditions for convertion of plastics in a bubbling fluidized bed reactor with diameter $0.1 \mathrm{~m}$ 
and height $1.0 \mathrm{~m}$. Sand with mean particle diameter of $305 \mu \mathrm{m}$ was used as the bed material, and the tests were carried out for different temperatures. The minimum fluidization velocities for steam were found to be $0.28 \mathrm{~m} / \mathrm{s}, 0.23 \mathrm{~m} / \mathrm{s}$ and $0.18 \mathrm{~m} / \mathrm{s}$ at temperatures $500^{\circ} \mathrm{C}, 550^{\circ} \mathrm{C}$ and $600^{\circ} \mathrm{C}$ respectively. CPFD simulations were performed to study the minimum fluidization velocity for steam at $600^{\circ} \mathrm{C}$. The computational result agreed well with the experimental data. The CFPD model was further used to study the conversion of biomass to a product gas. The product gas contained $22 \% \mathrm{CO}, 7.5 \% \mathrm{H}_{2}$ and $7 \% \mathrm{CH}_{4}$.

Based on the literature review, the experimental results and the simulations, this study recommends investigation of conversion of biomass and plastics in a bubbling fluidized bed reactor. The recommended operation temperature is $600^{\circ} \mathrm{C}$ or higher. It is important to operate the reactor well above the minimum fluidization velocity, and the biomass to plastics ratio should be properly chosen to avoid melting of plastics in the feeding system and in the reactor.

\section{REFERENCES}

[1] Geyer, R., Jambeck, J.R. \& Law, K.L., Production, use, and fate of all plastics ever made. Science Advances, 3(7), pp. e1700782-e1700782, 2017.

[2] Plastics Europe. www.plasticseurope.org/en/resources/market-data. Accessed on: 13 Feb. 2019.

[3] Basu, P., Biomass Gasification, Pyrolysis and Torrefaction: Practical Design and Theory, Elsevier: San Diego, 2013.

[4] PlasticsEurope, Plastics: The facts 2016. www.plasticseurope.org/Document/plastics--the-facts-2016-15787.aspx?FolID=2.

[5] Macpac. www.macpac.co.uk/wp-content/uploads/2018/06/recycling-process-graphic.jpg.

[6] Mastellone, M.L., Perugini, F., Ponte, M. \& Arena, U., Fluidized bed pyrolysis of a recycled polyethylene. Polymer Degradation and Stability, 76(3), pp. 479-487, 2002.

[7] Stevens, M.P., Polymer Chemistry: An Introduction, Oxford University Press, 1999.

[8] Ali, U., Karim, K.J.B.A. \& Buang, N.A., A review of the properties and applications of poly (methyl methacrylate) (PMMA). Polymer Reviews, 55(4), pp. 678-705, 2015.

[9] French, R. \& Czernik, S., Catalytic pyrolysis of biomass for biofuels production. Fuel Processing Technology, 91(1), pp. 25-32, 2010.

[10] Hornung, A., Transformation of Biomass: Theory to Practice, Wiley: New York, 2014.

[11] Chhabra, V., Shastri, Y. \& Bhattacharya, S., Kinetics of pyrolysis of mixed municipal solid waste-a review. Procedia Environmental Sciences, 35, pp. 513-527, 2016.

[12] Ratnasari, D.K., Nahil, M.A. \& Williams, P.T., Catalytic pyrolysis of waste plastics using staged catalysis for production of gasoline range hydrocarbon oils. Journal of Analytical and Applied Pyrolysis, 124, pp. 631-637, 2017.

[13] Rehan, M. et al., Effect of zeolite catalysts on pyrolysis liquid oil. International Biodeterioration and Biodegradation, 119, pp. 162-175, 2017.

[14] Miguel, G.S., Serrano, D.P. \& Aguado, J., Valorization of waste agricultural polyethylene film by sequential pyrolysis and catalytic reforming. Industrial and Engineering Chemistry Research, 48(18), pp. 8697-8703, 2009.

[15] Santaweesuk, C. \& Janyalertadun, A., The production of fuel oil by conventional slow pyrolysis using plastic waste from a municipal landfill. International Journal of Environmental Science and Development, 8(3), p. 168, 2017.

[16] Donaj, P.J., Kaminsky, W., Buzeto, F. \& Yang, W., Pyrolysis of polyolefins for increasing the yield of monomers' recovery. Waste Management, 32(5), pp. 840-846, 2012. 
[17] Williams, P.T. \& Williams, E.A., Fluidised bed pyrolysis of low density polyethylene to produce petrochemical feedstock. Journal of Analytical and Applied Pyrolysis, 51(1), pp. 107-126, 1999.

[18] Artetxe, M., Lopez, G., Elordi, G., Amutio, M., Bilbao, J. \& Olazar, M., Production of light olefins from polyethylene in a two-step process: Pyrolysis in a conical spouted bed and downstream high-temperature thermal cracking. Industrial and Engineering Chemistry Research, 51(43), pp. 13915-13923, 2012.

[19] Ren, T., Patel, M. \& Blok, K., Olefins from conventional and heavy feedstocks: Energy use in steam cracking and alternative processes. Energy, 31(4), pp. 425-451, 2006.

[20] Paradela, F., Pinto, F., Gulyurtlu, I., Cabrita, I. \& Lapa, N., Study of the co-pyrolysis of biomass and plastic wastes. Clean Technologies and Environmental Policy, 11(1), pp. 115-122, 2009.

[21] Paradela, F., Pinto, F., Ramos, A.M., Gulyurtlu, I. \& Cabrita, I., Study of the slow batch pyrolysis of mixtures of plastics, tyres and forestry biomass wastes. Journal of Analytical and Applied Pyrolysis, 85(1), pp. 392-398, 2009.

[22] Sebestyén, Z. et al., Catalytic pyrolysis of biomass and plastic mixtures using HZSM5 zeolite. Energy Procedia, 105, pp. 718-723, 2017.

[23] Xiang, Z., Liang, J., Morgan, H.M., Liu, Y., Mao, H. \& Bu, Q., Thermal behavior and kinetic study for co-pyrolysis of lignocellulosic biomass with polyethylene over cobalt modified ZSM-5 catalyst by thermogravimetric analysis. Bioresource Technology, 247, pp. 804-811, 2018.

[24] Chattopadhyay, J., Pathak, T.S., Srivastava, R. \& Singh A.C., Catalytic co-pyrolysis of paper biomass and plastic mixtures (HDPE (high density polyethylene), PP (polypropylene) and PET (polyethylene terephthalate)) and product analysis. Energy, 103, pp. 513-521, 2016.

[25] Snider, D.M., An incompressible three-dimensional multiphase particle-in-cell model for dense particle flows. Journal of Computational Physics, 170(2), pp. 523-549, 2001.

[26] Amarasinghe, W.S., Jayarathna, C.K., Ahangama, B.S., Moldestad, B.E.M. \& Tokheim, L.-A., Experimental study and CFD modelling of fluidization velocity for Geldart A, B and D particles. International Journal of Modelling and Optimization, 7(3), pp. 152-156, 2017. 